\title{
Evaluation of Fixed Biofilm Reactor (FBR) System with Tire Derived Rubber (TDR) Support Media for Remediation of Methylene Blue Dye from Wastewater
}

\author{
D. Naresh Yadav ${ }^{1,2}$, Iffat $\mathrm{Naz}^{2,3}$, K. Anand Kishore ${ }^{1 *}$, Devendra Saroj ${ }^{2 *}$ \\ ${ }^{1}$ Department of Chemical Engineering, National Institute of Technology, Warangal, India \\ ${ }^{2}$ Department of Civil and Environmental Engineering, University of Surrey, Guildford, GU2 \\ 7XH, United Kingdom \\ ${ }^{3}$ Department of Biology, Deanship of Educational Services, Qassim University, Buraidah, \\ KSA
}

Corresponding Authors*

Dr. K. Anand Kishore

Department of Chemical Engineering,

National Institute of Technology, Warangal, India

Emailkola@nitw.ac.in

Phone +91 9966541095, +918332969398

\section{Dr. Devendra P. Saroj}

Senior Lecturer, Water and Environmental Engineering

Department of Civil and Environmental Engineering

Faculty of Engineering and Physical Sciences

University of Surrey, Surrey GU2 7XH

United Kingdom

$\mathrm{T}+44(0) 1483-686634$

$\mathrm{F}+44(0) 1483-682135$

Keywords: Tire derived rubber (TDR), Biofilm, Methylene blue dye wastewater.

To cite and online access: D Naresh Yadav, Iffat Naz, K Anand Kishore, Devendra Saroj (2020). Evaluation of Fixed Biofilm Reactor (FBR) System with Tire Derived Rubber (TDR) Support Media for Remediation of Methylene Blue Dye from Wastewater. Environmental Technology. DOI: 10.1080/09593330.2020.1737736

Link: https://doi.org/10.1080/09593330.2020.1737736 


\begin{abstract}
The present investigation is focused on development of aerobic biofilm on tire derived rubber (TDR) media and then evaluation of such system for bioremediation of Methylene blue (MB) dye for 9 weeks. After 9 weeks of operation, the COD, BOD, ammonia and color values have been declined by $89.2,98.3,99.61$ and $99.81 \%$ respectively, While SEM-EDX results showed a variance in weight percent of various elements in TDR without biofilm i.e. raw TDR media, as well as in the $1^{\text {st }}$ and $9^{\text {th }}$ week samples. Moreover, fine and strong peaks were observed in both the MB simulated wastewater and $9^{\text {th }}$ week TDR samples at 1190, 1300, 1400, 1450, 1500 and $1618 \mathrm{~cm}^{-1}$ respectively by Raman Spectroscopic analysis. Further, FTIR analysis was performed for the MB simulated wastewater, and absorbance peaks ranging from 1591 to 1363 $\mathrm{cm}^{-1}$ and $3410 \mathrm{~cm}^{-1}$ were observed in all the samples with different intensities. To assess the biodeterioration of the TDR media, ATR was performed for the raw, $1^{\text {st }}, 2^{\text {nd }}$ and $9^{\text {th }}$ week TDR media samples and in the raw TDR, two important bands, 842 and $2962 \mathrm{~cm}^{-1}$ were noticed representing $-\mathrm{CH}=\mathrm{CH}$ and $-\mathrm{CH}_{3}$. A clear variation of bands and peak intensities were observed in different support media samples. The results indicate that TDR media is a resilient, chemically resistant material and could be employed for the biofilm growth for biological treatment of textile dye wastewater.
\end{abstract}

Keywords: Tire derived rubber (TDR), Biofilm, Methylene blue dye wastewater. 


\section{Introduction:}

Wastewater treatment has gained significant attention in recent years. Based upon the type of contaminants available in the wastewater, i.e., chemical and physical various types of processes are established. ${ }^{1}$ Each process has its own advantages and disadvantages, such as their cost and environmental issues. Therefore, currently the treatment of wastewater using biological sources is gaining much attention. ${ }^{2}$ Biological processes are simple to execute, maintenance cost is low and poses less risk to the environment as compared to other methods. These processes can be divided into submerged/attached and dispersed/suspension system depending on the configuration of biomass structure. ${ }^{3}$ The submerged system has advantage over dispersed process as growth of the biomass is supported by a solid support medium (SSM). ${ }^{4}$ Further, advantages offered by these systems are flexible in operation, less space requirement, decreased hydraulic retention times, less effect on corresponding environment, increase in biomass weight, low sludge production, superior biomass residence time, and superior capability to degrade complex compounds. 5,6

In attached growth systems, biofilm formation is achieved by the attachment of microbes to the surface of the support media by the production of Extracellular Polymeric Substances (EPSs). ${ }^{7,8}$ It is followed by the cell division resulting in monolayer formation and then new microbes are bound along with the debris present in the wastewater, creates three-dimensional polymer structures resulting in interconnection and immobilization of the microbial cells. ${ }^{9}$ While, biofilm growth on the surfaces of the SSM is maintained by various different types of nutrients present in the wastewater. These nutrients are exposed to biomass by velocity gradient in the system. ${ }^{10}$ Moreover, various factors that affect the formation of biofilm are temperature, the surface topology of support media, velocity, turbulence, hydrodynamics, production of EPS and divalent cations. ${ }^{11,12}$ Further, the configuration of biomass/biofilm on the SSM also depends upon its chemical composition, interactions between living cells and polymer molecules of the available surface. ${ }^{13} \mathrm{SSM}$ is basic component of the submerged system, its basic purpose is to provide much-needed support for biofilm growth and it should be chemically resistant, durable and insoluble. The selection of the SSM, depends upon its size, density, porosity and importantly it should be resistant to chemicals and erosion. ${ }^{7}$ The ideal SSM should have low cost, good surface area, high porosity to promote aeration and avoid clogging. ${ }^{14,15}$ While, SSM used in the system could be of natural (sand, soil, stones, gravel and rocks), or artificial (plastic, glass and rubber). ${ }^{16}$ So far different types of SSM have been employed for the wastewater treatment in biofilm reactors such as pebbles, ${ }^{4,17}$ tire-derived rubber, ${ }^{18}$ polypropylene ${ }^{19}$ and 
polystyrene. ${ }^{20}$ The chemical nature of the SSM is necessary for its better compatibility with biofilm. Thus, for in-depth characterization of the material used as SSM in the bioreactors, various microscopic and spectroscopic techniques to be employed include; scanning electron microscopy (SEM), Fourier transform infrared spectroscopy (FTIR), energy dispersive x-ray spectroscopy (EDX), Raman Spectroscopy (RS) and X-ray photoelectron spectroscopy (XPS).

Across the world, $7 \times 10^{5}$ tons of various commercial dyes are produced annually. More than $90 \%$ of the total dyes produced are used by the textile industries. During the process of dyeing, about $10-15 \%$ of the dye will be vanished and come out with the effluent. For several purposes including dying silk, wool, cotton and other textiles the cationic methylene blue dye is utilised often. ${ }^{21,22}$ Organic molecules are utilised in manufacturing the most of the Synthetic dyes. Majority of the dyes are defiant to environmental circumstances and are appallingly biodegradable. In textile industries, apart from the dyes few chemicals are also used. The effluents released from the textile industries are carcinogenic and are threat to aquatic and human life. These dye effluents distract the biological process upon interacting with the light sources. At the time of chlorination, the dyes generate trihalomethanes and also they have the ability to obstruct the gases solubility in water. Tissue necrosis, quadriplegia, jaundice, cyanosis, shock, vomiting, increase in heartbeat of humans are some of the deleterious/biological effects of the dyes. ${ }^{23}$ The governments are working on bringing up some stringent environmental legislations to control these implications. Certain laws are already in existence which directs the industries about the concentration limits of pollutants before discharge. $^{24}$

The aim of the present study is the employment of tire-derived rubber (TDR) as solid support media (SSM) for the biofilm growth in aerobic bioreactor for the treatment of methylene blue (MB) simulated wastewater. In order to achieve this aim, the objectives include characterization of the chemical composition of the TDR SSM by XPS, SEM EDX and Raman Spectroscopy for confirmation of its compatibility with biofilms grown on its surface, and characterization of the biofilms on the TDR SSM by SEM-EDX, FTIR, ATR and Raman Spectroscopy. The characterisation of samples also included estimation of the physico-chemical parameters, $\mathrm{COD}, \mathrm{BOD}, \mathrm{pH}$, colour and Ammonia ion concentration throughout the experimental duration of the influent and effluent of the bioreactors to check the metabolic activities of the biofilm. This study also reveals the process dynamics and reactions taking place in the sludge samples and the SSM at different time intervals which are used to explore the 
physiological activities of the biofilm systems. In addition, this research work establishes the potential of the TDR SSM aerobic bioreactors for effective dye wastewater treatment.

\section{Materials and Methods}

\subsection{Selection and characterization of the chemical composition of media}

Discarded tires were cut into small cubic pieces, with a surface area of $5.92 \mathrm{~cm}^{2}$. The elemental composition of the TDR pieces were determined by X-ray photoelectron spectroscopic (XPS) analysis using a Theta probe spectrometer (Thermo Fisher Scientific, East Grinstead, UK). XPS spectra is obtained by employing X-ray Al K $\alpha$ monochromatic source (hv $=1486.6 \mathrm{eV})$; an X-ray spot of radius $\sim 400 \mu \mathrm{m}$ was used. Initially, survey spectra was acquired by passing the energy at 300 and $50 \mathrm{eV}$; the high-resolution core level spectra of individual elements such as $\mathrm{C} 1 \mathrm{~s}, \mathrm{O} 1 \mathrm{~s}, \mathrm{Ca} 2 \mathrm{p}$ and N1s present in the TDR was acquired. Also, $80 \mathrm{eV}$ Pass Energy was used for the other high resolution core level spectra. ${ }^{19,25}$ Ensuing the non-linear background removal, the quantitative surface chemical analyses was enumerated from the high resolution core level spectra, according to various researchers. ${ }^{4,26-29}$ After the XPS characterization the TDR pieces were washed and sterilized by autoclaving at $121^{\circ} \mathrm{C}$ for 20 minutes and later they are transferred in to the bioreactor.

\subsection{Experimental setup}

Fig 1 demonstrates the schematic illustration of the laboratory scale experimental setup for MB dye simulated wastewater treatment. Two bioreactors (height $19.05 \mathrm{~cm}$, radius $6.95 \mathrm{~cm}$ and capacity of $2891.93 \mathrm{~cm}^{3}$ ) of 1 litre volume each one is used in this experimental study. Aquarium Air pumps - AP4 equipped with the stone diffusers were connected to the reactors for the aeration and for continuous mixing of the dye wastewater (Fig 1). The sterilized TDR pieces were transferred into both the reactors and covered with the perforated material in order to maintain aerobic conditions. This experiment was performed in a fume cupboard under aseptic conditions and the bioreactors were set into operational condition in continuous batch mode at room temperature. The activated sludge sample was collected from a wastewater treatment plant in Guildford, Surrey (UK) in sterilized nalgean bottles $(1000 \mathrm{~mL})$ and used as a seed for colonization of bacterial community on TDR SSM. In order to maintain the homogeneity of the reactor, the feed transfer in to the reactor and the sample collection from the reactor were performed at equal rate and time intervals.

Figure 1 here 


\subsubsection{Composition of simulated Methylene Blue (MB) contaminated wastewater}

The synthetic textile MB dye wastewater is prepared in the laboratory and utilized in the present experimental study. Composition of the MB dye simulated wastewater solution was mentioned in the Table 1, its composition was considered according to previous research reports. ${ }^{30,31}$ The high purity grade $(>90 \%)$ chemicals utilized in this experimental study were procured from Sigma - Aldrich (Gillingham, United Kingdom) and MB dye (C16H18CIN3S) was purchased from M/s Sisco Research Laboratories Pvt. Ltd. Maharashtra, India. The simulated wastewater solution was prepared for 5 litres in a 10 litre container and mixed thoroughly with a magnetic stirrer. The $\mathrm{pH}$ of the simulated wastewater solution was adjusted to 8.5 using acetic acid of $1 \mathrm{~N}$. This experiment was carried out for 9 weeks in a fume cupboard at room temperature. The organic substrate source was added to the bioreactors at regular time intervals (Every second day).

\section{Table 1 here}

\subsubsection{Experimental operation}

The $100 \mathrm{ml}$ of sludge sample was transferred in to each reactor. The microbial community present in the sludge sample multiplies and tends to form a layer around the TDR SSM. After configuration of the active biofilms on TDR SSM, the treatment efficiency of the reactors was determined for simulated MB wastewater. Initially, $50 \mathrm{ml}$ of simulated wastewater and sludge were added to the bioreactors in the ratio of $1: 4,2: 3,3: 2$, and $4: 1$ on Day $3,5,7$, and 9, respectively for acclimatization. Later on, from Day 11, $50 \mathrm{ml}$ of simulated wastewater was added till the end of the experiment. Simultaneously on every second day of the experiment, $50 \mathrm{ml}$ of samples were collected from the two bioreactors for the characterization studies. In order to maintain the homogeneity of the reactor, the feed transfer in to the reactor and the sample collection from the reactor were performed at equal rate $(50 \mathrm{ml})$ and time intervals (2 days).

\subsubsection{Physico-chemical characterization of simulated Methylene blue (MB) influents and effluents}

The organic matter contents of water samples (influents and effluents) were accessed as 5-day $\mathrm{BOD}_{5}$ and COD with standard methods (SMs): $5210 \mathrm{~B}$ and $5220 \mathrm{D}$ respectively. While, true colour was measured in line with the Hach Spectrophotometry method 8025, adapted from SM- 
$2120 \mathrm{C}$, and $\mathrm{pH}$ was measured using a bench-top pH probe (Hanna: HI 2210), as according to the standard methods. ${ }^{32}$ Chemical changes in MB simulated wastewater before and after $\left(1^{\text {st }}\right.$, $2^{\text {nd }}$ and 9th weeks) treatment, were analysed by the FTIR (Agilent Cary 640 FTIR). The spectra of FTIR were scanned at 500 to $4000 \mathrm{~cm}^{-1}$ in triplicates by $\mathrm{KBr}$ pressed-disk technique. ${ }^{33}$

\subsection{Characterization of the surface of tire derived rubber (TDR) solid support media (SSM) \\ 2.3.1 Scanning electron microscopic (SEM) analysis of the tire derived rubber (TDR) solid support media (SSM)}

TDR surface characterization was achieved by employing SEM-EDX (JEOL JSM-7100F). For scanning electron microscopic (SEM) analysis, thin rubber sections with biofilm were taken from the reactor and immersed in $0.2 \mathrm{molL}^{-1}$ phosphate buffer. The samples were then washed twice and fixed. The fixed samples were dehydrated (KADA 85 U/SMD) for 2 min and coated with gold. The coated samples were examined under SEM at $1000 \times$ and $3000 \times$.

\subsubsection{Raman Spectroscopic analysis of the tire derived rubber (TDR) solid support media (SSM)}

Raman microscopic technique is applied in the present research for chemical investigation of the TDR SSM before (raw TDR) and after $\left(1^{\text {st }}\right.$ and $9^{\text {th }}$ week TDR SSM samples) the treatment. Further, MB simulated wastewater sample was also examined by Raman. All Raman spectra were recorded using a Raman Microscope (RENISHAW in via confocal Raman microscope, STFC Rutherford Appleton Laboratory [RAL], UK). The Raman signals were collected in the spectral interval $600-2000 \mathrm{~cm}^{-1}$; at $830 \mathrm{~nm}$ wavelength laser source with integration time of $10 \mathrm{~s}$. The experiments were performed at $5 \mathrm{X}$ objective extended scan using 50 pc power and 5 accumulations.

\subsubsection{Attenuated total reflection (ATR) analysis of the tire derived rubber (TDR) solid support media (SSM)}

ATR technique was applied for the determination of Biodeterioration of TDR SSM by using Agilent Cary 640 with a Specac diamond ATR. The $1^{\text {st }}, 2^{\text {nd }}$ and the $9^{\text {th }}$ week TDR SSM samples were collected from the reactor and then, the biofilms were removed from the surface of the TDR SSM samples using phosphate buffer and later the SSMs were dried. ATR analysis was performed in triplicates for the dried and raw TDR SSM samples in the range of 500 to 4000 $\mathrm{cm}^{-1}$.

\section{Results and Discussion}


The potency and the resilience of the TDR SSMs for the biofilm growth have been assessed in the current research work. This study also revealed the most suitable stage (metabolically active) of microbial growth, having a maximum potential to treat wastewater and more compatible, durable and inert media to be used in FBR. It is necessary to select the best-support media and the active stage of biofilm to be employed in FBRs, because their treatment efficiency depends on the compatibility of filter media with microbes of developing biofilms.

\subsection{Estimation of the chemical composition of tire derived rubber (TDR) solid support media (SSM) by X-ray photoelectron spectroscopy (XPS)}

For the efficient wastewater treatment, substantial support media and metabolically active biofilms are required. ${ }^{34}$ Hence, it is consequential to check whether the elemental composition of the support media is suitable for the microbial population or not. ${ }^{29}$ The raw TDR SSM was characterized by using X-ray photoelectron spectroscopy (XPS). This analysis is considered as the most effective chemical composition characterization method for thin surface layers. Further, the complete information such as the chemical state, type of bonds, etc. of the elements is provided by the XPS analysis. Generally, the rubber material is made up of oxygen, carbon, nitrogen and hydrogen. Most of its properties and surface structure depend on the combination of these elements. ${ }^{35}$ In this present research, on characterizing the TDR SSM, the elements identified over the surface are C (88.42\%), O (8.28\%), Ca (1.24\%), N (069\%), Si (1.08\%), $\mathrm{Cl}(0.14 \%), \mathrm{Na}(0.08 \%)$ and $\mathrm{Zn}(0.07 \%)$ (Fig 2).

\section{Figure 2 here}

Martinez et al. ${ }^{36}$ studied the impact of thermal ageing on Ethylene-Propylene-Diene Elastomer (rubber) surface degradation. In their research work, on characterizing the elastomer using XPS, the carbon was identified as the crucial element in the spectra and this might be because of the elastomer polymer structure. Because of the presence of additives in the elastomer, the other elements such as zinc, silicon, nitrogen and etc. are observed in minimal quantities. $^{35,37}$ The biofilms exhibit different diversities with change in the elemental composition of the support media. ${ }^{38}$ Ellis et al. ${ }^{39}$ studied the effects of carbon source and other Parameters on heterotrophic biofilm bacteria and observed that, the higher growth rates were possible with mixed carbon sources, chlorine and humics. Park et al. ${ }^{40}$ investigated the removal of hydrogen sulfide odor by developing a biofilter using TDR particle media. From the obtained results of the current research and comparing with the previous studies, it can be concluded that the TDR SSM has non-toxic elements and hence it can be used for the growth of biofilm 
for the dye wastewater treatment under aerobic conditions. The elements such as zinc, silicon, nitrogen, etc. which are observed in minimal quantities could be used as biofilters. ${ }^{440}$ The results also have shown the presence of carbon content in good amount, which favours the microbial population growth and ultimately favours the biofilm formation.

\subsection{Start-up phase of the tire derived rubber fixed biofilm reactor (TDR-FBR)}

For the efficient wastewater treatment, substantial support media and metabolically active biofilms are required. ${ }^{34}$ Previous studies have revealed that, for the biofilm development in a fixed film reactor, it requires 3-60 days of time. ${ }^{15,41,42}$ By inoculating activated sludge into the attached growth reactors/suspended growth process or by using purchased microbial cultures the start-up periods of fixed-film wastewater treatment reactors could be reduced. ${ }^{43,44} \mathrm{Naz}$ et al. ${ }^{25}$ reported that, to attain the start-up phase, the TDR pieces were immersed in the activated sludge for 2 weeks and later they were transferred to the FBR for the treatment of wastewater. Yu et al. ${ }^{15}$ investigated the impact of grain slag media on wastewater treatment and reported the start-up phase as 7 weeks. For the COD removal in a stable operation, Moore et al. ${ }^{41}$ reported the momentary start-up phase as 3 days. Naz et al. ${ }^{29}$ studied the impact of filter media chemical constituents on microbial population present in the sludge biofilms and reported the start-up phase as 14 days. Various changes in the physico chemical parameters were observed in 9 weeks of experimental work and these changes are due to the metabolic activities of the microbial population present in the sludge sample. ${ }^{45}$ The start-up phase of the current research was 9 days.

\subsection{Monitoring of physicochemical parameters in the effluent during the biofilm formation}

The sludge wastewater from the Guildford wastewater treatment plant was used for the biofilm development on the TDR SSM. The simulated wastewater and sludge were added in the proportion of $1: 4,2: 3,3: 2$, and $4: 1$ on day $3,5,7$, and 9 , respectively for acclimatization. It took 9 days for the biofilm development on the SSM and it was considered as the start-up phase for the wastewater treatment. Later on, from Day 11, $50 \mathrm{ml}$ of simulated wastewater was added to the reactors till the end of the experiment. Various physicochemical parameters of influent and effluent were monitored at regular intervals $\left(0,1^{\text {st }}, 2^{\text {nd }}, 3^{\text {rd }}, 4^{\text {th }}, 5^{\text {th }}, 6^{\text {th }}, 7^{\text {th }}, 8^{\text {th }}\right.$ and $9^{\text {th }}$ week $)$ including $\mathrm{COD}, \mathrm{BOD}, \mathrm{pH}$, ammonia ions and color.

Assessment of COD has always been considered important, as it accounts for the amount of oxygen that is required for the oxidation and decomposition of organic and inorganic 
material in the sludge and simulated wastewater. Initially, the COD value of the activated sludge was $950 \mathrm{mg} / \mathrm{L}$. In this experiment, the COD loading rate of simulated wastewater was fixed as $2000 \mathrm{mg} / \mathrm{L}$. After the $1^{\text {st }}$ week, the COD values were significantly reduced to $650 \mathrm{mg} / \mathrm{L}$ and after 9 weeks of experiment, the values were further reduced to $216 \mathrm{mg} / \mathrm{L}$. Overall, $89.2 \%$ of COD was removed in 9 weeks experimental duration, i.e. from 2000 to $216 \mathrm{mg} / \mathrm{L} .{ }^{46,47} \mathrm{Naz}$ et al. ${ }^{48}$ treated the wastewater using biofilms developed on the stone support media and observed $74.5 \%$ of COD removal under aerobic conditions in 9 weeks. And the researchers have revealed that the bacterial biofilm developed on the SSM was the main reason for the COD removal. Kim et al. ${ }^{49}$ studied the textile wastewater treatment by integrating the chemical coagulation, fluidized biofilm and electrochemical oxidation methods. $68.8 \%$ of COD removal was observed in the individual fluidized biofilm reactor. With the contribution of the fluidized biofilm reactor, $25.7 \%$ of excess COD was removed by the integrated system. The excess COD removal was possible because of the biofilm developed on the support media. And also in the individual fluidized biofilm reactor, the researchers have performed the experiments with and without support media and observed more COD removal in the presence of support media. It was because of the microbial community which easily gets attached to the support media and the attached microbial population tends to form an EPS matrix and eventually reduces the COD. Naz et al. ${ }^{38}$ reported $81.9 \%$ of COD removal in wastewater treatment by employing biological trickling filter packed with rubber media. The utilization of packing medium (rubber) for the bio-filtrations and biological transformations of organic matter by biofilm matrices are the major reasons for the efficient organic removal. And also, Naz et al. ${ }^{25}$ reported 93.9\% of COD removal from wastewater in TDR-FBR system under aerobic conditions. From the obtained results and based on the previous literature, the reasons for the COD decline could be due to the effective breakdown of the organic contaminants by the microorganisms present in the sludge and biofilm. ${ }^{4,50}$ The COD values of influent and various weeks' effluent samples were shown in Table 2.

The concentration of BOD is one of the most important pollution indicators that help in measuring the amount of organic decomposition taking place through the microbial community in the aqueous environment. The biodegradation rate of the wastewater and the organic pollution load are determined by BOD. ${ }^{51}$ The Initial BOD value of the sludge sample was 62.2 $\mathrm{mg} / \mathrm{L}$ and initial BOD of simulated wastewater was $1095.5 \mathrm{mg} / \mathrm{L}$. After the $1^{\text {st }}$ week, the BOD values were greatly reduced to $333.8 \mathrm{mg} / \mathrm{L}$ and after the $9^{\text {th }}$ week, the BOD values were further reduced to $8.17 \mathrm{mg} / \mathrm{L}$. Overall, $98.3 \%$ of BOD removal was observed by the end of 9 weeks, 
i.e., from 1095.5 to $18.17 \mathrm{mg} / \mathrm{L}$. The bacteria and the organic compounds present in the sludge sample have utilized more quantity of $\mathrm{O}_{2}$ for their oxidation, and this was the reason for high concentration of BOD initially. ${ }^{4}$ And during 9 weeks experimental period, due to the high breakdown of organic contaminants the BOD decline took place. Mack et al. ${ }^{52}$ studied the microbial film development by employing trickling filters and observed the tremendous decline of BOD. And this decline was due to the presence of microbes within the biofilm and this was experimentally confirmed. Naz et al. ${ }^{38}$ reported $86.4 \%$ of $\mathrm{BOD}_{5}$ removal was observed in wastewater treatment by employing biological trickling filter packed with rubber media. Wanner et al. ${ }^{53}$ worked on the biofilm cultivation by the activated sludge process and observed the higher BOD elimination in a hybrid system. And the experimental results have revealed that the presence of two types of microorganisms in the hybrid system was the reason for the high BOD removal. Naz et al. ${ }^{25}$ reported $92.7 \%$ of BOD removal from wastewater in TDR-FBR system under aerobic conditions. Similarly, Naz et al. ${ }^{48}$ treated the wastewater using biofilms developed on the stone support media and observed $70.9 \%$ of BOD removal in 9 weeks of time under aerobic conditions. And researchers have reported that the BOD reduction was due to the high biodegradation of organic matter by oxidation. From the obtained results and previous studies, it can be concluded that the BOD decline was due to the presence of microbial communities, which are actively digesting organic pollutants.

Further, Research on activated sludge has revealed that bacteria could survive in the range of 4-9 $\mathrm{pH}$. The $\mathrm{pH}$ of sludge (6.2) combined with the simulated wastewater (8.5) was monitored over 9 weeks under the experimental conditions. The $\mathrm{pH}$ of the samples in the bioreactors was decreased till $3^{\text {rd }}$ week and later a slight variation of $7.80 \pm 0.5$ was observed. The variations in the $\mathrm{pH}$ were because of the concurrent depletion of COD and BOD. ${ }^{45} \mathrm{Naz}$ et al. ${ }^{29}$ reported the neutral $\mathrm{pH} 7.30 \pm 0.2$ for the treatment of wastewater using biofilm developed on rubber media under aerobic conditions. Sedlak et al. ${ }^{54}$ worked on activated sludge systems and observed that the bacteria were activated in the $\mathrm{pH}$ range $4-9.35$. The activity and synthesis of proteins that are connected with various cellular operations are swiftly regulated by the bacteria in retaliation to any variation in $\mathrm{pH}$. But few processes like polysaccharides do not adjust simply with $\mathrm{pH}$ changes. For the generation of polysaccharides, the favourable $\mathrm{pH}$ condition changes from organism to organism, however $\mathrm{pH} 7$ is the favourable condition for most of the bacteria. ${ }^{55,56} \mathrm{pH}$ of influent and effluent of various weeks were represented in table 2. 
Moreover, changes in the concentration of ammonia ions were also studied during the biofilm growth on TDR SSM in order to determine the physiological activities of autotrophic microbes. Ammonia concentration of sludge was $20.1 \mathrm{mg} / \mathrm{L}$ and simulated wastewater was $1300 \mathrm{mg} / \mathrm{L}$. The concentration of ammonia ions increased in the $2^{\text {nd }}$ week and later started decreasing from $3^{\text {rd }}$ to $9^{\text {th }}$ week of the experiment. The increase in ammonia concentration in the $2^{\text {nd }}$ week might be due to the presence of microbes which gain metabolically productive energy from the oxidation of organic nitrogen to ammonium. ${ }^{57}$ However, ammonia was reduced to $5 \mathrm{mg} / \mathrm{L}(99.61 \%)$ by the end of $9^{\text {th }}$ week. This could be due to the ammonification, the $\mathrm{NH}_{2}$ groups present in the sample gets converted into ammonia or its ionic form ammonium $\left(\mathrm{NH}_{4}^{+}\right)$ as an end product. ${ }^{58}$ Ammonia concentrations of the influent and effluent of various weeks were represented in table 2 .

Further, change in color of the effluent was also observed during the experiment. From the experimental results, the color intensity increased by $2^{\text {nd }}$ week and later on decreased by the $3^{\text {rd }}$ week, this indicates the deterioration of MB dye by metabolic activities of microorganisms in biofilm. The sudden increase of color in the $2^{\text {nd }}$ week was due to the addition of increased quantity of concentrated simulated wastewater to the bioreactors in regular intervals. Finally, color intensity reduced tremendously to $1043.75 \mathrm{Pt} / \mathrm{Co}(99.81 \%)$ by the end of the experiment, as indicated in table 2. ${ }^{59}$ Uysal and Bilgiç et al. ${ }^{60}$ studied the removal of color by chemical and biological process in aerobic filter reactors by using two step treatment system, and observed 96.4\% Pt/Co color removal for $800 \mathrm{ppm}$ initial dye concentration. The authors have concluded that the up flow packed bed biological-chemical reactors can be utilized for the color removal of textile dye wastewaters. Another research group has reported the color removal in textile wastewaters by the combination of bacterial and fungal treatment. Because of the mixed bacterial population, a very minimal color removal (adsorption) was observed from the experimental results. ${ }^{61}$ In the current study, $99.81 \%$ of color removal was observed from the obtained results, i.e. from $566666.66 \mathrm{Pt} / \mathrm{Co}$ to $1043.75 \mathrm{Pt} / \mathrm{Co}{ }^{62}$

\section{Table 2 here}

FTIR analysis was performed for the liquid samples (simulated MB dye wastewater, $1^{\text {st }}, 2^{\text {nd }}$ and $9^{\text {th }}$ week samples of the bioreactor) in order to determine the removal of dye from the effluent. The weekly collected experimental liquid samples were compared with the MB simulated wastewater and explained in the Fig 3. The gradual development of the peaks with increase in time can be observed in the Fig 3. The absorbance peaks ranging from 1591 to 1363 
$\mathrm{cm}^{-1}$ and $3410 \mathrm{~cm}^{-1}$ were observed in the MB spectrum. The peaks 1591 to $1363 \mathrm{~cm}^{-1}$ represents the aromatic ring structures present in $\mathrm{MB}$ dye ${ }^{63}$ and the peak at $3410 \mathrm{~cm}^{-1}$ attributed to ANH/AOH overlapped stretching vibration absorbance. ${ }^{64}$ Various researchers have compared the MB dye adsorption by EDTAD-modified magnetic baker's yeast and magnetic baker's yeast. From the FTIR analysis, $1140 \mathrm{~cm}^{-1}, 1442 \mathrm{~cm}^{-1}, 1572 \mathrm{~cm}^{-1}$ and $3410 \mathrm{~cm}^{-1}$ absorbance peaks were identified in the MB spectra.

\section{Figure 3 here}

The authors have reported that, $1140 \mathrm{~cm}^{-1}$ peak from the amide III band functional group specified the bending band of NH. ${ }^{65,66}$ They have assigned $1442 \mathrm{~cm}^{-1}$ and $1572 \mathrm{~cm}^{-1}$ peaks $\mathrm{CO}, \mathrm{CN}$ and $\mathrm{COOH}$ respectively and $2928 \mathrm{~cm}^{-1}$ band was attributed to $\mathrm{CH}$ of $\mathrm{CH}_{2}$ symmetrical stretching band. Further, the band at $3410 \mathrm{~cm}^{-1}$ was assigned to NH/OH overlapped stretching vibration absorbance. ${ }^{64}$ From the present study results, it was observed that, with increase in time period the peak intensity has decreased. It might be because of the degradation of MB dye by the microbial population that was formed as a biofilm matrix on the surface of the TDR SSM.

\subsection{Characterization of tire derived rubber (TDR) solid support media (SSM) surface and biofilms by SEM-EDX}

The physiological activity of the biomass that takes place on the surface of the support media influences the treatment efficiency of the attached growth bioreactor. Various previous studies have revealed the different support media properties and their impact on microbial appendage, development and performance of the bioreactor. ${ }^{34,38,67}$ Elemental composition of TDR SSM before and after exposure to sludge and associated biofilm formation were examined by using SEM-EDX. The results have revealed the presence of various elements such as carbon, silicon, oxygen, magnesium, aluminium, potassium, calcium, iron and zinc before development of biofilm (i.e. raw TDR SSM). After the $9^{\text {th }}$ week of experiment, the TDR SSM has undergone many changes which can be observed from the Fig 4. From the SEM-EDX results, clear differences were observed in the elemental composition of the different samples. The surface of the $9^{\text {th }}$ week sample was rough, porous and uneven which was completely covered with the microbial aggregates in the form of EPS. The group of peaks related to the particular elements and their concentrations were reported by EDX analysis. The weight percent of the carbon, iron, silica and zinc reduced to 18.6, 1.5, 16.9 and 2.0 from 25.1, 7.3, 22.6 and 8.7\%. And few other elements such as oxygen, magnesium, aluminium and calcium increased from 21.8, 1.4, 
8.1 and 2.2 to $35.9,2.5,8.9$ and 9.5 respectively in 9 weeks. This could be due to the different chemical and biological reactions that took place between the microbial communities of sludge sample and the components present in the simulated MB solution. The surface has become corrosive and also many scrapes and cracks were identified. This might be due to the presence of large microbial community along with the components of the MB simulated wastewater on the surface of the TDR SSM ${ }^{4}$ (Fig 4). And also the colonization of large microbial population on the surface may lead to the degradation of the TDR SSM. ${ }^{68}$

\section{Figure 4 (a-f) here}

Park et al. ${ }^{40}$ has developed the biofilm on the TDR support media and identified plentiful similar microbial community on the surface using SEM analysis. Another scientific group reported that, the biofilms developed on various support media such as rice root surfaces, glass and polystyrene manifested distinct degrees of maturation. ${ }^{69} \mathrm{Naz}$ et al. ${ }^{4}$ reported that the presence of the non-toxic elements in the TDR support media favours the biofilm growth for the treatment of wastewater. Further, Hirai et al. ${ }^{70}$ studied the $\mathrm{H}_{2} \mathrm{~S}$ removal characteristics in different inorganic packing materials and reported that a good media has large surface area, high porosity and at low density and long-time operations it experiences minimal change in character. Scientists have studied and reported that, the biofilms developed on the SSMs can be further used for the wastewater treatment. ${ }^{71}$ Thus, the biofilms developed on the TDR SSM under aerobic conditions can be concluded as the best/Ideal method for the wastewater treatment. ${ }^{68}$

\subsection{Evaluation of tire derived rubber (TDR) solid support media (SSM) and degradative changes in methylene blue by Raman Spectroscopy}

Raman Spectroscopy analyses were performed for the MB simulated wastewater, raw TDR, $1^{\text {st }}$ and $9^{\text {th }}$ week TDR SSMs (Fig 5). The main absorption peaks of MB simulated wastewater solution bands were observed at $1618 \mathrm{~cm}^{-1}$ at stretching vibration of $\mathrm{C}=\mathrm{O}$. The characteristic Raman bands of the MB simulated wastewater solution were strong. Few other peaks in the simulated wastewater solution are aromatic compounds, $\mathrm{C}=\mathrm{C}, \mathrm{CH}_{2}, \mathrm{CH}_{3}$, alicyclic and aliphatic compounds, C=S, O-O, C-S at 1500, 1400, 1300, 1190, 890, 780 Wavenumbers (cm

$\left.{ }^{1}\right)$ respectively. In the raw TDR SSM sample, no fine peaks were appeared between $1500 \mathrm{~cm}^{-1}$ to $1700 \mathrm{~cm}^{-1}$. In the $9^{\text {th }}$ week TDR SSM sample, we have noticed that the MB simulated wastewater was adsorbed by the TDR surface and the MB band was shifted slightly away from $1618 \mathrm{~cm}^{-1}$. The Raman band which was observed in the $9^{\text {th }}$ week TDR sample was fine and 
strong. ${ }^{72}$ Few peaks which are noticed in the MB simulated wastewater solution were also observed in the $9^{\text {th }}$ week TDR sample. The bands at $1500,1400,1450,1300$ and $1190 \mathrm{~cm}^{-1}$ were identified in the $9^{\text {th }}$ week TDR sample. A scientific group investigated the composition, structure and development of fully hydrated biofilms by using confocal Raman micro spectroscopy (CRM). Cellular core round colonies bounded in a wrapped EPS form were observed on the flow cell surface. The EPS has enhanced uninterruptedly and proliferated completely. Some of the characteristic peaks of early PAO1 bacterial biofilms are; $\delta(\mathrm{C}-\mathrm{H})$ band at $1450 \mathrm{~cm}^{-1}$ for nucleic acids and proteins. 1760 and $1520 \mathrm{~cm}^{-1}$ are the amide region indicating peaks from the water, $1200-1000 \mathrm{~cm}^{-1}$ is the polysaccharide region includes C-O stretching and phosphates. $1006 \mathrm{~cm}^{-1}$ is the phenylalanine peak, 1400 and $1200 \mathrm{~cm}^{-1}$ are the amide III region which also includes lipids, polysaccharides and nucleic acids. And at $780 \mathrm{~cm}^{-}$ 1 , the nucleic acid peaks were observed.

\section{Figure 5 here}

Using the treated bacteria, the spectra of these early biofilm colonies were compared and it was observed that their spectra's are much alike and only minimal changes that occur due to change in numbers and cell positions could be identified. ${ }^{73}$ Ramirez-Mora et al. ${ }^{72}$ investigated the characterization of vital components of A. naeslundii, E. faecalis and dual-species biofilm matrices by employing Raman spectroscopy method. From the obtained results it was observed that, the proteins, nucleic acids, fatty acids and carbohydrates were present in all the biofilm samples. An intense band around $1300 \mathrm{~cm}^{-1}$ which might be an amino acid/ $\mathrm{CH}_{3}$ group was observed in the A. naeslundii spectra. And bands identified at 1445 and $1500 \mathrm{~cm}^{-1}$ were attributed to $\mathrm{CH}_{2}$ group. These results are consistent with the results of the current research. Hence, from the observed results and the previous experimental studies, it can be concluded that surface-associated communities with diverse macromolecules which are also known as EPSs were formed on the surface of the TDR SSM and these formed biofilms have absorbed the major dye component i.e. the MB dye used in this experimental study. Fig 6 explains the Raman peak shifts shown by MB simulated wastewater, TDR SSM without biofilm (raw), $1^{\text {st }}$ and $9^{\text {th }}$ week TDR SSMs with mature biofilms.

\section{Figure 6 here}

\subsection{Determination of degradative changes in tire derived rubber (TDR) solid support media (SSM) by Attenuated total reflection (ATR)}


Further, ATR technique was applied to determine the Biodeterioration of TDR SSM. ${ }^{74-77}$ ATR is also a good way to determine the chemical composition of various polymeric substances and the chemical reactions that take place on the surface of those polymeric materials under different conditions. ${ }^{78}$ The raw and the collected TDR SSM samples at different weeks were characterized using ATR (shown in Fig 7). In the raw TDR SSM, two important bands, 842 $\mathrm{cm}^{-1}$ and $2962 \mathrm{~cm}^{-1}$ were noticed which represents $-\mathrm{CH}=\mathrm{CH}$ and $-\mathrm{CH}_{3}{ }^{79}$ Low intensity peaks at $1464 \mathrm{~cm}^{-1}$ and $1541 \mathrm{~cm}^{-1}$ specifying $\mathrm{C}=\mathrm{C}$ were observed in the $1^{\text {st }}$ and $2^{\text {nd }}$ week TDR SSM samples. The band 2861 and $2921 \mathrm{~cm}^{-1}$ was observed in the $1^{\text {st }}$ and $2^{\text {nd }}$ week TDR SSM samples indicate the $\mathrm{C}-\mathrm{H}$ bond. The peaks 1591 to $1363 \mathrm{~cm}^{-1}$ represents the aromatic ring structures present in $\mathrm{MB}$ dye ${ }^{63}$ and the peak at $3410 \mathrm{~cm}^{-1}$ attributed to $\mathrm{ANH} / \mathrm{AOH}$ overlapped stretching vibration absorbance. ${ }^{4,64}$ The peak intensity at $1591 \mathrm{~cm}^{-1}$ of $9^{\text {th }}$ week TDR SSM was stronger than the $1^{\text {st }}$ week sample. The intensity of the MB peak was increased with the time and this was because of the diminution of the MB dye, a clear variation of bands and peak intensities is shown in Fig 7. Many researchers have reported that EPS matrix comprises of large microbial population in aggregates and there is a chance of attack on the TDR SSM by various microbial populations present in the biofilm matrix. ${ }^{80-83}$ Previously it was reported that the chemical variations that take place in rubber relate to the oxidative degradation of polymeric structures such as neoprene, isoprene, butadiene and styrene by extracellular oxidative enzymes and this result in the carbonyl and/or aldehyde groups' generation. The vigorous polymeric nature integrated with various retardants, adhesives and vulcanizing agents determines the durability of the TDR SSM. ${ }^{4}$ In the current study, the TDR SSMs had under gone a very minimal chemical changes and this specifies that the TDR SSM is an efficient media for the biofilm development in FBR under aerobic conditions and eventually useful for the wastewater treatment.

\section{Figure 7 here}

\section{Conclusions}

The biofilm growth on the tire derived rubber (TDR) solid support media (SSM) for Methylene blue (MB) dye wastewater treatment under aerobic conditions was evaluated in this study for 9 weeks. TDR SSM's elemental composition, as biofilm support surface, was analysed by XPS and observed that the TDR SSM constitutes of $\mathrm{C}, \mathrm{O}, \mathrm{Ca}, \mathrm{N}, \mathrm{Si}, \mathrm{Cl}, \mathrm{Na}$ and $\mathrm{Zn}$ elements. The TDR SSM has shown exceptional results in terms of biofilm growth and MB dye removal from the wastewater. The physico-chemical parameters such as COD, BOD, ammonia and color were reduced remarkably by $89.2 \%, 98.3 \%, 99.61 \%$ and $99.81 \%$ respectively in 9 weeks. The 
gradual growth of the biofilm on the TDR surface was clearly observed in SEM images. In Raman spectrum, fine, sharp and strong Raman bands were identified in the $9^{\text {th }}$ week sample, which indicates the adsorption of MB dye by the biofilm on the TDR SSM. The surface analysis of the liquid and TDR SSM samples were analysed using FTIR and ATR. Clear variations in the spectroscopy bands were identified. This pilot scale experiment has provided significant results in treating the MB dye simulated wastewater using TDR SSM as a robust biofilm support media. Hence, the findings can be utilised for designing and operating a large scale trial and further application to address the problem of water pollution from textile industry wastewater, prevalent in many developing countries. The results also clearly indicate that the TDR SSM is a long lasting, efficient and economical biofilm support media for dye wastewater treatment using biofilm systems under aerobic conditions.

\section{Acknowledgements:}

This research project was funded jointly by the British Council, UK and the Department of Biotechnology (DBT), MHRD, India under the Newton Bhabha Fellowship Program. The authors would like to extend heartfelt gratitude to Dr Steven Hinder (Materials Science and Engineering), Mr David Jones and Rhys Mayer (Centre for Engineering Materials), Judy Peters and Max Attwood (Department of Chemistry), Caryn Jones (Department of Civil and Environmental Engineering) of the University of Surrey, UK and Mr. Aditya of NIT Warangal. The Authors also wish to acknowledge Professor Tony Parker, STFC Rutherford Appleton Laboratory (RAL), UK for the Raman Spectroscopy analysis and the Director NITW for all the other support.

\section{Conflict of interest}

The authors declare that they have no conflicting interests.

\section{Ethical approval}

This article does not contain any studies with human participants or animals performed by any of the authors.

\section{References}

1. Ahn, D. H., Chang, W. S. \& Yoon, T. Il. Dyestuff wastewater treatment using chemical oxidation, physical adsorption and fixed bed biofilm process. Process Biochem. 34, 429-439 (1999).

2. Oller, I., Malato, S. \& Sánchez-Pérez, J. A. Combination of Advanced Oxidation 
Processes and biological treatments for wastewater decontamination-A review. Sci. Total Environ. 409, 4141-4166 (2011).

3. Kornaros, M. \& Lyberatos, G. Biological treatment of wastewaters from a dye manufacturing company using a trickling filter. J. Hazard. Mater. 136, 95-102 (2006).

4. Naz, I. et al. Appraisal of the tire derived rubber (TDR) medium for wastewater treatment under aerobic and anaerobic conditions. J. Chem. Technol. Biotechnol. 89, 587-596 (2014).

5. Martin, K. J. \& Nerenberg, R. The membrane biofilm reactor (MBfR) for water and wastewater treatment: Principles, applications, and recent developments. Bioresour. Technol. 122, 83-94 (2012).

6. $\quad$ Lewandowski, Z. \& Boltz, J. P. Biofilms in Water and Wastewater Treatment. Treatise on Water Science 4, (2010).

7. Michael Givskov_Staffan Kjelleberg-The biofilm mode of life _ mechanisms and adaptations-Horizon Bioscience (2007).pdf.

8. Li, J., Luan, Z., Zhu, B., Gong, X. \& Dangcong, P. Effects of colloidal organic matter on nitrification and composition of extracellular polymeric substances in biofilms. $J$. Chem. Technol. Biotechnol. 77, 1333-1339 (2002).

9. Muda, K. et al. Development of granular sludge for textile wastewater treatment. Water Res. 44, 4341-4350 (2010).

10. Sfaelou, S., Karapanagioti, H. K. \& Vakros, J. Studying the Formation of Biofilms on Supports with Different Polarity and Their Efficiency to Treat Wastewater. J. Chem. 2015, 1-7 (2015).

11. Ansari, F. A., Jafri, H., Ahmad, I. \& Abulreesh, H. H. Factors Affecting Biofilm Formation in in vitro and in the Rhizosphere . Biofilms Plant Soil Heal. 275-290 (2017). doi:10.1002/9781119246329.ch15

12. Krivorot, M., Kushmaro, A., Oren, Y. \& Gilron, J. Factors affecting biofilm formation and biofouling in membrane distillation of seawater. J. Memb. Sci. 376, 15-24 (2011).

13. Boks, N. P., Norde, W., van der Mei, H. C. \& Busscher, H. J. Forces involved in bacterial adhesion to hydrophilic and hydrophobic surfaces. Microbiology 154, 31223133 (2008).

14. Christensson, M. \& Welander, T. Treatment of municipal wastewater in a hybrid process using a new suspended carrier with large surface area. Water Sci. Technol. 49, 207-214 (2004).

15. Yu, Y., Feng, Y., Qiu, L., Han, W. \& Guan, L. Effect of grain-slag media for the treatment of wastewater in a biological aerated filter. Bioresour. Technol. 99, 41204123 (2008).

16. Paridah, M. et al. We are IntechOpen, the world' s leading publisher of Open Access books Built by scientists, for scientists TOP $1 \%$. Intech i, 13 (2016).

17. Swamy, J. \& Ramsay, J. A. The evaluation of white rot fungi in the decoloration of textile dyes. Enzyme Microb. Technol. 24, 130-137 (1999).

18. Khatoon, N. et al. Bacterial succession and degradative changes by biofilm on plastic medium for wastewater treatment. J. Basic Microbiol. 54, 739-749 (2014).

19. Naz, I. et al. Monitoring of growth and physiological activities of biofilm during succession on polystyrene from activated sludge under aerobic and anaerobic 
conditions. Environ. Monit. Assess. 185, 6881-6892 (2013).

20. Matos, M., Alves, C., Campos, J. L., Brito, A. G. \& Nogueira, R. Sequencing batch biofilm reactor: From support design to reactor operation. Environ. Technol. 32, 11211129 (2011).

21. Mohammed, M. a, Shitu, a \& Ibrahim, a. Removal of Methylene Blue Using Low Cost Adsorbent: A Review. Res. J. Chem. Sci. 4, 91-102 (2014).

22. Belisti Lelisa, M. M. Removal of Methylene Blue (Mb) Dye from Aqueous Solution by Bioadsorption onto Untreated Parthenium hystrophorous Weed. Mod. Chem. Appl. 02, (2014).

23. Paulino, A. T. et al. Removal of methylene blue dye from an aqueous media using superabsorbent hydrogel supported on modified polysaccharide. J. Colloid Interface Sci. 301, 55-62 (2006).

24. Tsai, W. T. et al. Adsorption of acid dye onto activated carbons prepared from agricultural waste bagasse by $\mathrm{ZnCl} 2$ activation. Chemosphere 45, 51-58 (2001).

25. Naz, I., Rehman, A., Sehar, S., Perveen, I. \& Ahmed, S. Assessment of an integrated tire-derived rubber media-fixed biofilm reactor (TDR-FBR) and sand column filter (SCF) for wastewater treatment at low temperature. Desalin. Water Treat. 99, 185-195 (2017).

26. Verheyde, B., Havermans, D. \& Vanhulsel, A. Characterization and tribological behaviour of siloxane-based plasma coatings on HNBR rubber. Plasma Process. Polym. 8, 755-762 (2011).

27. Mattox, D. M. Substrate ("Real") Surfaces and Surface Modification. Handbook of Physical Vapor Deposition (PVD) Processing (1998). doi:10.1016/b978-0815514220.50003-6

28. Alazmi, A. et al. A process to enhance the specific surface area and capacitance of hydrothermally reduced graphene oxide. Nanoscale 8, 17782-17787 (2016).

29. Naz, I. et al. Effect of the chemical composition of filter media on the microbial community in wastewater biofilms at different temperatures. RSC Adv. 6, 104345 104353 (2016).

30. Asenjo, J. A. \& Andrews, B. A. Mini-review Challenges and trends in bioseparations. Chem. Eng. 120, 117-120 (2008).

31. Ma, D. Y. et al. Aerobic granulation for methylene blue biodegradation in a sequencing batch reactor. Desalination 276, 233-238 (2011).

32. Federation, W. E. <Apha 2012 Standard Methods.Pdf > . (1999).

33. Nicolet, T. How to prepare IR samples ? 1-3 (2016). doi:10.1530/jrf.0.0860679

34. $\mathrm{Xu}, \mathrm{X}$. Y. et al. Biofilm formation and microbial community analysis of the simulated river bioreactor for contaminated source water remediation. Environ. Sci. Pollut. Res. 19, 1584-1593 (2012).

35. Martnez, L., Romn, E. \& Nevshup, R. X-Ray Photoelectron Spectroscopy for Characterization of Engineered Elastomer Surfaces. Adv. Asp. Spectrosc. (2012). doi:10.5772/48101

36. Martínez, L., Nevshupa, R., Felhös, D., De Segovia, J. L. \& Román, E. Influence of friction on the surface characteristics of EPDM elastomers with different carbon black contents. Tribol. Int. 44, 996-1003 (2011). 
37. Yang, Z., Peng, H., Wang, W. \& Liu, T. Crystallization behavior of poly( $\varepsilon^{-}$ caprolactone)/layered double hydroxide nanocomposites. J. Appl. Polym. Sci. 116, 2658-2667 (2010).

38. Naz, I., Saroj, D. P., Mumtaz, S., Ali, N. \& Ahmed, S. Assessment of biological trickling filter systems with various packing materials for improved wastewater treatment. Environ. Technol. (United Kingdom) 36, 424-434 (2015).

39. Ellis, B. D., Butterfield, P., Jones, W. L., McFeters, G. A. \& Camper, A. K. Effects of carbon source, carbon concentration, and chlorination on growth related parameters of heterotrophic biofilm bacteria. Microb. Ecol. 38, 330-347 (1999).

40. Park, J., Evans, E. A. \& Ellis, T. G. Development of a biofilter with tire-derived rubber particle media for hydrogen sulfide odor removal. Water. Air. Soil Pollut. 215, 145153 (2011).

41. Moore, R., Quarmby, J. \& Stephenson, T. The effects of media size on the performance of biological aerated filters. Water Res. 35, 2514-2522 (2001).

42. Mijaylova Nacheva, P., Chávez, G. M., Bustos, C., Zúñiga, M. A. G. \& Orozco, Y. H. Comparison of bioreactors with different kinds of submerged packed beds for domestic wastewater treatment. Water Sci. Technol. 58, 29-36 (2008).

43. Sharvelle, S., McLamore, E. \& Banks, M. K. Hydrodynamic Characteristics in Biotrickling Filters as Affected by Packing Material and Hydraulic Loading Rate. $J$. Environ. Eng. 134, 346-352 (2008).

44. Zhou, L., Bai, X., Li, Y. \& Ma, P. Immobilization of Micro-Organism on Macroporous Polyurethane Carriers. Environ. Eng. Sci. 25, 1235-1242 (2008).

45. Naz, I., Seher, S., Perveen, I., Saroj, D. P. \& Ahmed, S. Physiological activities associated with biofilm growth in attached and suspended growth bioreactors under aerobic and anaerobic conditions. Environ. Technol. (United Kingdom) 36, 1657-1671 (2015).

46. Park, H. O., Oh, S., Bade, R. \& Shin, W. S. Application of A2O moving-bed biofilm reactors for textile dyeing wastewater treatment. Korean J. Chem. Eng. 27, 893-899 (2010).

47. Balapure, K., Bhatt, N. \& Madamwar, D. Mineralization of reactive azo dyes present in simulated textile waste water using down flow microaerophilic fixed film bioreactor. Bioresour. Technol. 175, 1-7 (2015).

48. Naz, I., Seher, S., Perveen, I., Saroj, D. P. \& Ahmed, S. Physiological activities associated with biofilm growth in attached and suspended growth bioreactors under aerobic and anaerobic conditions. Environ. Technol. (United Kingdom) 36, 1657-1671 (2015).

49. Kim, T. H., Park, C., Lee, J., Shin, E. B. \& Kim, S. Pilot scale treatment of textile wastewater by combined process (fluidized biofilm process-chemical coagulationelectrochemical oxidation). Water Res. 36, 3979-3988 (2002).

50. Sá, C. S. A. \& Boaventura, R. A. R. Biodegradation of phenol by Pseudomonas putida DSM 548 in a trickling bed reactor. Biochem. Eng. J. 9, 211-219 (2001).

51. Eke, P. E. \& Scholz, M. Benzene removal with vertical-flow constructed treatment wetlands. J. Chem. Technol. Biotechnol. 83, 55-63 (2008).

52. Mack, W. N., Mack, J. P. \& Ackerson, A. O. Microbial film development in a trickling filter. Microb. Ecol. 2, 215-226 (1975). 
53. Wanner, J., Kucman, K. \& Grau, P. Activated sludge process combined with biofilm cultivation. Water Res. 22, 207-215 (1988).

54. Second, P. Phosphorus and Nitrogen Removal_book.pdf.

55. Oliveira, R., Melo, L., Oliveira, A. \& Salgueiro, R. Polysaccharide production and biofilm formation by Pseudomonas fluorescen: effects of $\mathrm{pH}$ and surface material. Colloids Surfaces B Biointerfaces 2, 41-46 (1994).

56. Sehar, S. \& Naz, I. Role of the Biofilms in Wastewater Treatment. in Microbial Biofilms - Importance and Applications (InTech, 2016). doi:10.5772/63499

57. Yun, H. J. \& Kim, D. J. Nitrite accumulation characteristics of high strength ammonia wastewater in an autotrophic nitrifying biofilm reactor. J. Chem. Technol. Biotechnol. 78, 377-383 (2003).

58. Strock, J. S. Ammonification. Encycl. Ecol. 162-165 (2009). doi:10.1016/b978008045405-4.00256-1

59. Hosseini Koupaie, E., Alavi Moghaddam, M. R. \& Hashemi, S. H. Post-treatment of anaerobically degraded azo dye Acid Red 18 using aerobic moving bed biofilm process: Enhanced removal of aromatic amines. J. Hazard. Mater. 195, 147-154 (2011).

60. Uysal, Y. \& Bilgiç, M. Color removal from wastewater by using two-step (biological and chemical) aerobic filter reactors. Glob. Nest J. 20, 7-13 (2018).

61. Novotný, Č. et al. Potential of combined fungal and bacterial treatment for color removal in textile wastewater. Bioresour. Technol. 102, 879-888 (2011).

62. de Souza, S. M. de A. G. U., Bonilla, K. A. S. \& de Souza, A. A. U. Removal of COD and color from hydrolyzed textile azo dye by combined ozonation and biological treatment. J. Hazard. Mater. 179, 35-42 (2010).

63. Pradhan, A. C., Paul, A. \& Rao, G. R. Sol-gel-cum-hydrothermal synthesis of mesoporous Co-Fe@A12O3-MCM-41 for methylene blue remediation. J. Chem. Sci. 129, 381-395 (2017).

64. Xia, Y., Yao, Q., Zhang, W., Zhang, Y.\& Zhao, M. Comparative adsorption of methylene blue by magnetic baker's yeast and EDTAD-modified magnetic baker's yeast: Equilibrium and kinetic study. Arab. J. Chem. (2015). doi:10.1016/j.arabjc.2015.03.010

65. Mahmoud, M. E., Yakout, A. A. \& Osman, M. M. Dowex anion exchanger-loadedbaker's yeast as bi-functionalized biosorbents for selective extraction of anionic and cationic mercury(II) species. J. Hazard. Mater. 164, 1036-1044 (2009).

66. Burattini, E. et al. A FTIR microspectroscopy study of autolysis in cells of the wine yeast Saccharomyces cerevisiae. Vib. Spectrosc. 47, 139-147 (2008).

67. Wu, W., Liu, Y., Zhu, Q., Wei, C. \& Wang, J. Remediation of polluted river water by biological contact oxidation process using two types of carriers. Int. J. Environ. Pollut. 38, 223 (2009).

68. Brunswick, N. ACCELERATED PAPER BIODEGRADABILITY OF SOME FOOD. 25, (1993).

69. Zhou, Y. \& Gao, X. Characterization of Biofilm Formed by Phenanthrene-Degrading Bacteria on Rice Root Surfaces for Reduction of PAH Contamination in Rice. (2019).

70. Hirai, M., Kamamoto, M., Yani, M. \& Shoda, M. Comparison of the biological NH3 
removal characteristics among four inorganic packing materials. J. Biosci. Bioeng. 91, 428-430 (2001).

71. Weftec ${ }^{\circledR} .06 .3217-3230$ (2006).

72. Ramirez-Mora, T., Dávila-Pérez, C., Torres-Méndez, F. \& Valle-Bourrouet, G. Raman Spectroscopic Characterization of Endodontic Biofilm Matrices. J. Spectrosc. 2019, 17 (2019).

73. Sandt, C., Smith-Palmer, T., Pink, J., Brennan, L. \& Pink, D. Confocal Raman microspectroscopy as a tool for studying the chemical heterogeneities of biofilms in situ. J. Appl. Microbiol. 103, 1808-1820 (2007).

74. Kiatkamjornwong, S., Sonsuk, M. \& Wittayapichet, S. Degradation of styrene-gcassava starch $®$ lled polystyrene plastics. 66, 323-335 (1999).

75. Klrbas, Z., Keskin, N. \& Güner, A. Biodegradation of Polyvinylchloride ( PVC ) by White Rot Fungi. 335-342 (1999).

76. E, C. A., In, A. \& O, B. L. L. Ó. P. E. Z. Poly ( Vinylalcohol- Co -Ethylene ) Biodegradation on Semi Solid Fermentation by Phanerochaete chrysosporium. 23, 123-128 (2004).

77. Dř , P., Hoffmann, J. \& Druz, M. ARTICLE IN PRESS POLYMER Evaluating the aerobic biodegradability of plastics in soil environments through GC and IR analysis of gaseous phase. 26, 729-741 (2007).

78. Whitehouse, R. S., Counsell, P. J. C. \& Lewis, G. Composition of rubber/resin adhesive films: 1. Surface composition as determined by ATR spectroscopy. Polymer (Guildf). 17, 699-704 (1976).

79. Manohar, N. et al. A unique application of the second order derivative of FTIR-ATR spectra for compositional analyses of natural rubber and polychloroprene rubber and their blends. Polym. Test. 62, 447-453 (2017).

80. Kay, M. J., McCabe, R. W. \& Morton, L. H. G. Chemical and physical changes occurring in polyester polyurethane during biodegradation. Int. Biodeterior. Biodegrad. 31, 209-225 (1993).

81. Rose, K. \& Steinbüchel, A. Biodegradation of natural rubber and related compounds: Recent insights into a hardly understood catabolic capability of microorganisms. Appl. Environ. Microbiol. 71, 2803-2812 (2005).

82. Yikmis, M. \& Steinbüchel, A. Historical and recent achievements in the field of microbial degradation of natural and synthetic rubber. Appl. Environ. Microbiol. 78, 4543-4551 (2012).

83. Ali Shah, A., Hasan, F., Shah, Z., Kanwal, N. \& Zeb, S. Biodegradation of natural and synthetic rubbers: A review. Int. Biodeterior. Biodegrad. 83, 145-157 (2013).

\section{Words count: 8615}

\section{Legend for Figures}

Figure 1. Schematic illustration of the experimental setup for simulated dye wastewater treatment. 
Figure 2. X-ray photoelectron spectroscopic (XPS) survey of raw tire derived rubber (TDR) solid support media (SSM).

Figure 3. Fourier-transform infrared spectroscopy (FTIR) spectra of methylene blue (MB simulated wastewater, $1^{\text {st }}, 2^{\text {nd }}$ and $3^{\text {rd }}$ week's liquid samples of the bioreactors.

Figure 4. Scanning electron micrographs (SEM) (A) and EDX (B) before configuration of the biofilm on tire derived rubber (TDR) solid support media (SSM) (raw TDR), (C) \& (D) TDR SSM after $1^{\text {st }}$ week of biofilm development and (E) \& (F) TDR SSM surface with 9 weeks mature biofilm.

Figure 5. Raman Spectra of raw tire derived rubber (TDR), $1^{\text {st }}, 9^{\text {th }}$ week solid support media (SSM) and methylene blue (MB) simulated wastewater.

Figure 6. Raman peaks shifts between $1400-1700 \mathrm{~cm}^{-1}$ of methylene blue (MB) simulated wastewater, raw tire derived rubber (TDR) without biofilm, $1^{\text {st }}$ and $9^{\text {th }}$ weeks tire derived rubber (TDR) solid support media (SSM) with mature biofilms.

Figure 7. Attenuated total reflection (ATR) spectra of raw, $1^{\text {st }}, 2^{\text {nd }}$ and $3^{\text {rd }}$ weeks tire derived rubber (TDR) solid support media (SSM).

\section{Legend for Tables}

Table 1. Composition of simulated Methylene Blue (MB) simulated wastewater

Table 2. Changes observed in various physico-chemical parameters of the influent and effluent during 9 weeks of experiments under aerobic conditions. 


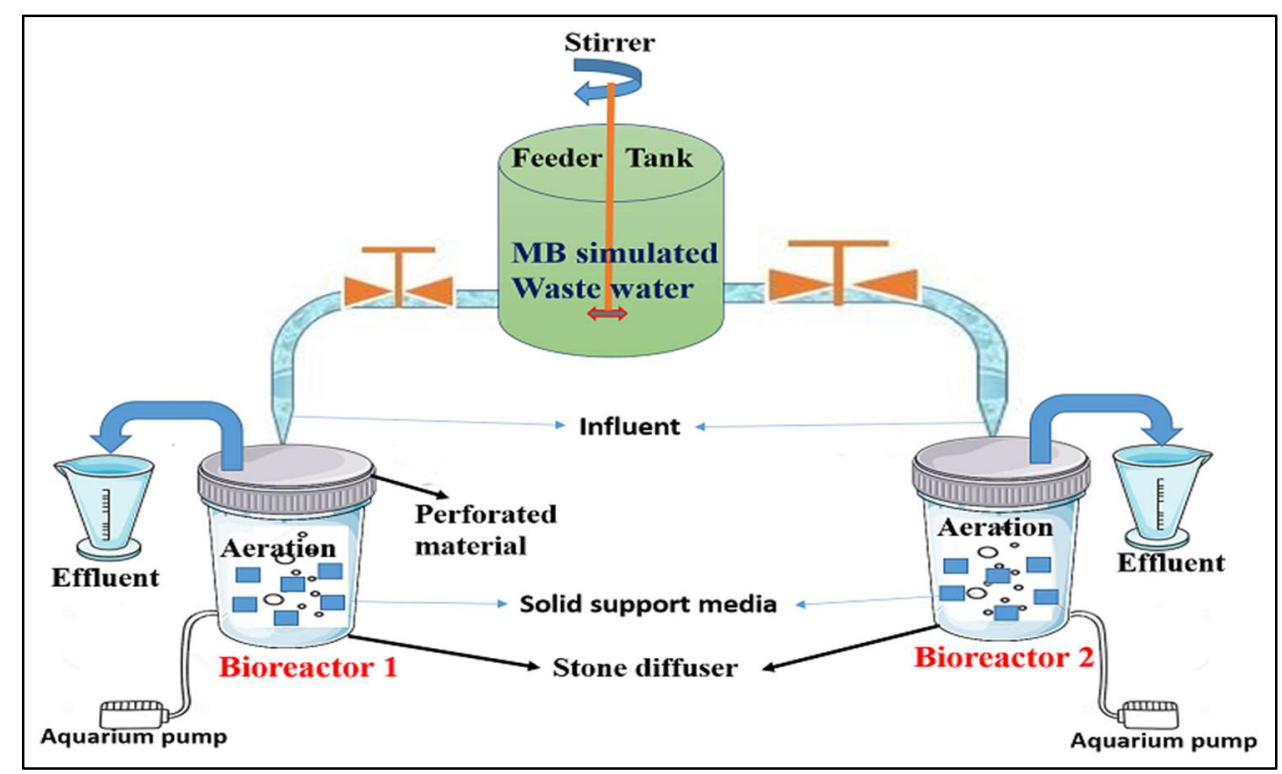

Figure 1



Figure 2 


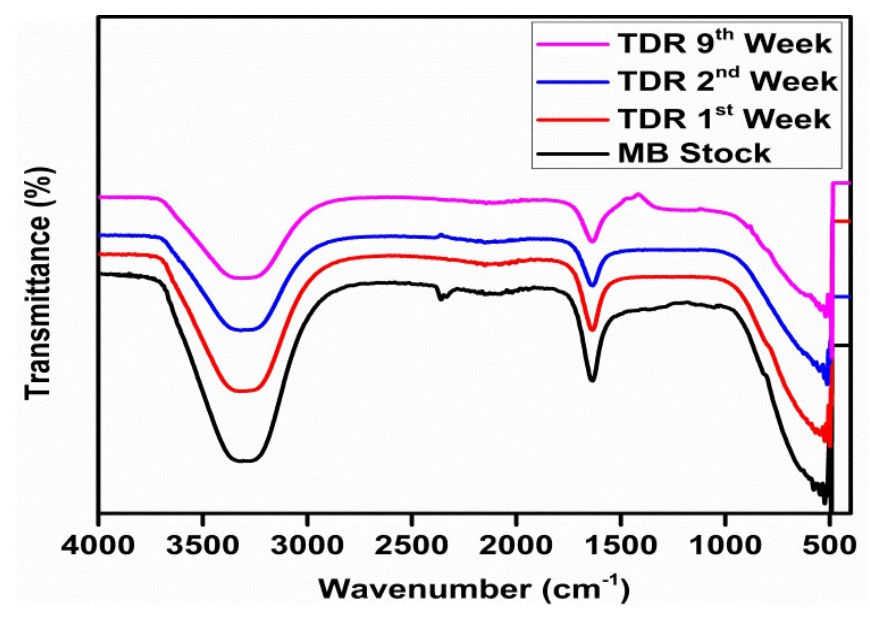

Figure 3
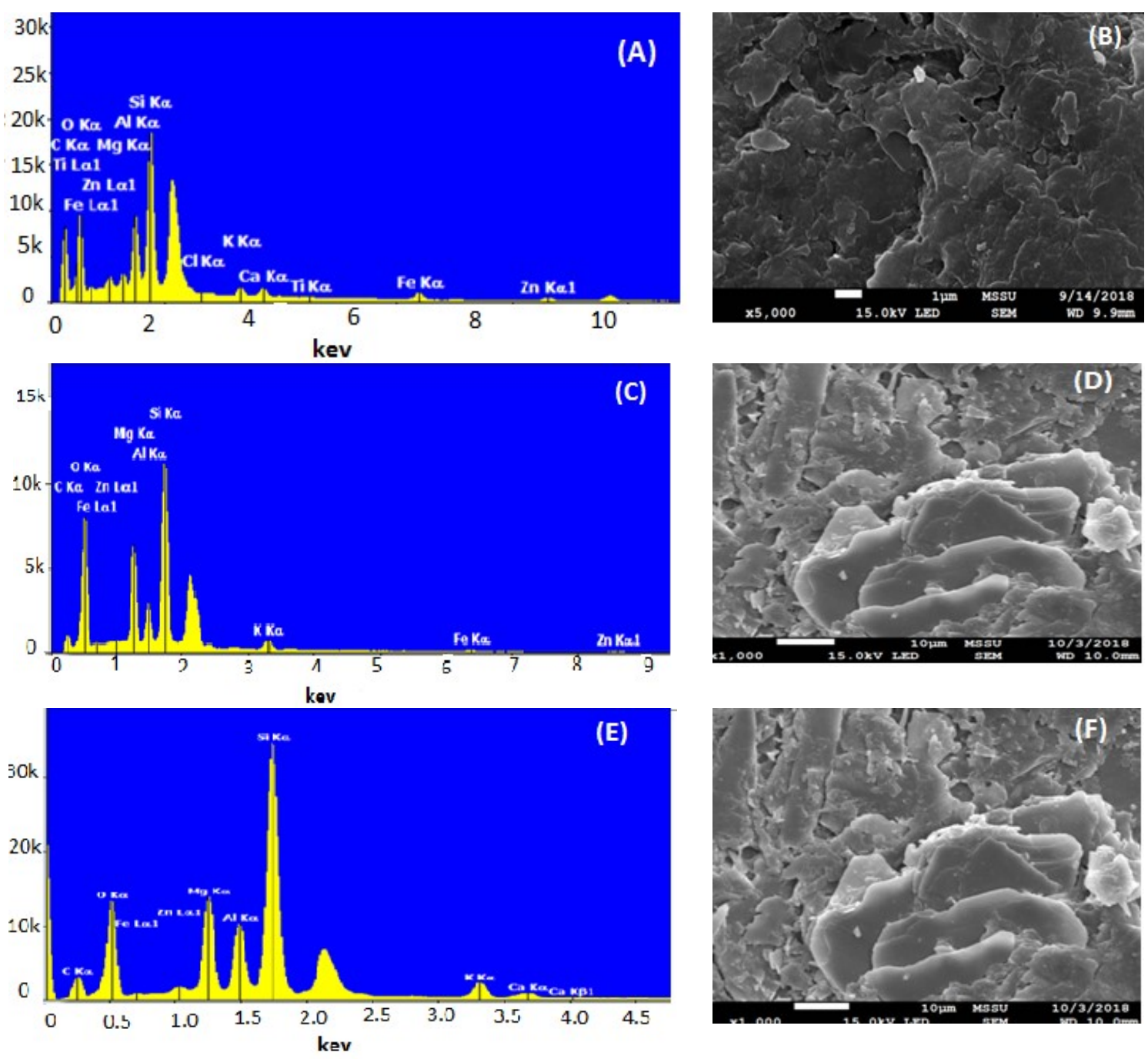

Figure 4 


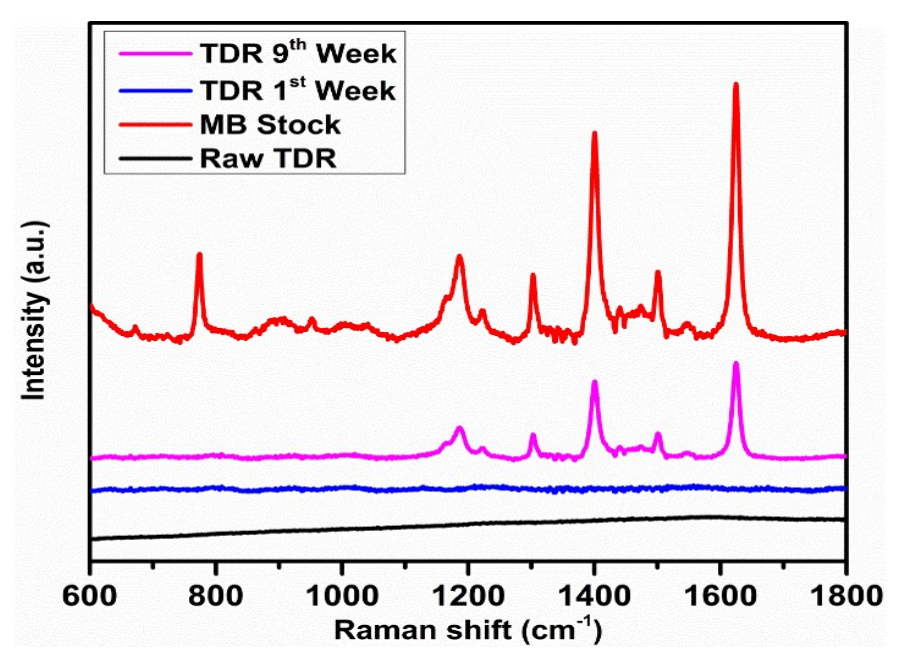

Figure 5
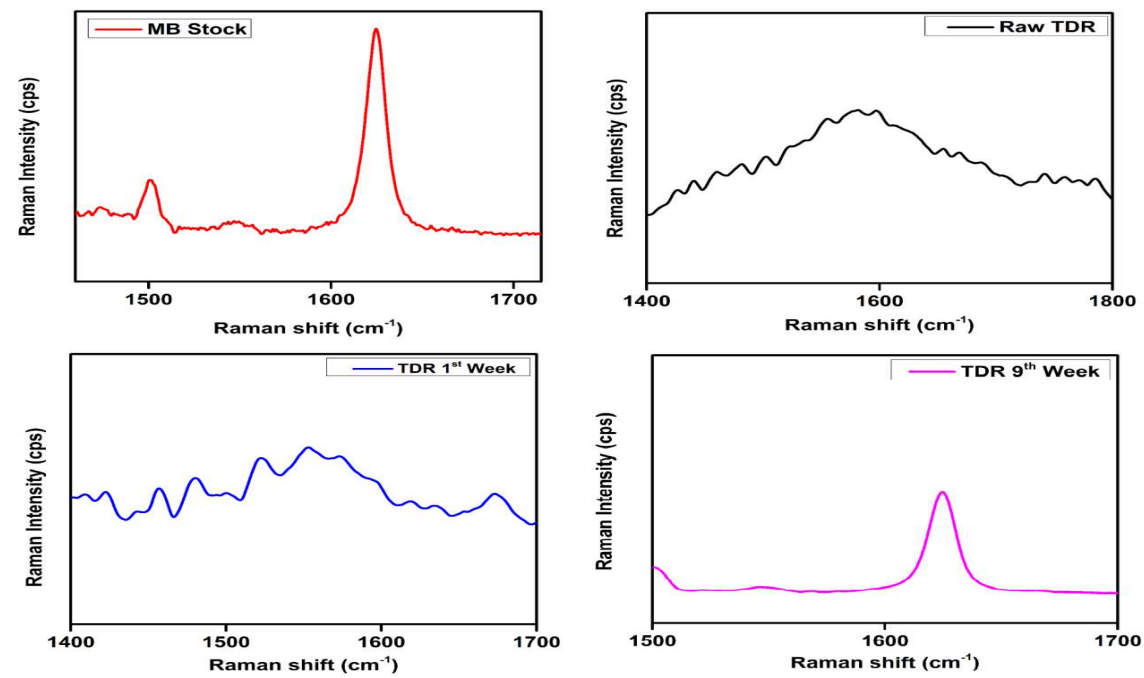

Figure 6

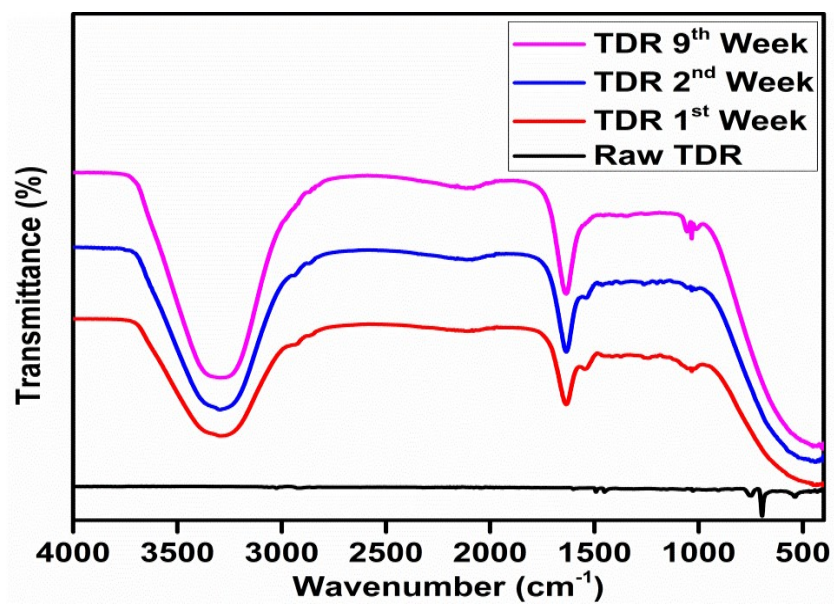




\section{Figure 7}

Table 1. Composition of simulated Methylene Blue (MB) simulated wastewater

\begin{tabular}{|c|l|c|}
\hline S.No & \multicolumn{1}{|c|}{ Composition } & Quantity (g/L) \\
\hline 1 & Sodium hypochlorite & 0.0224 \\
\hline 2 & Sodium chloride & 0.007 \\
\hline 3 & Ammonium nitrate & 0.1761 \\
\hline 4 & Magnesium chloride hexahydrate & 0.0034 \\
\hline 5 & Calcium chloride dihydrate & 0.004 \\
\hline 6 & Dibasic potassium phosphate trihydrate & 0.0367 \\
\hline 7 & Sodium benzoate & 0.1071 \\
\hline 8 & Sodium acetate & 0.2049 \\
\hline 9 & Ferric sulfate heptahydrate & 0.0084 \\
\hline 10 & Yeast extract & 0.0084 \\
\hline 11 & Soy oil & 0.224 \\
\hline 12 & Urea & 0.420 \\
\hline 13 & Peptone & 0.112 \\
\hline 14 & Methylene blue (dye) & 5 \\
\hline
\end{tabular}


Table 2. Changes observed in various physico-chemical parameters of the influent and effluent during 9 weeks of experiments under aerobic conditions.

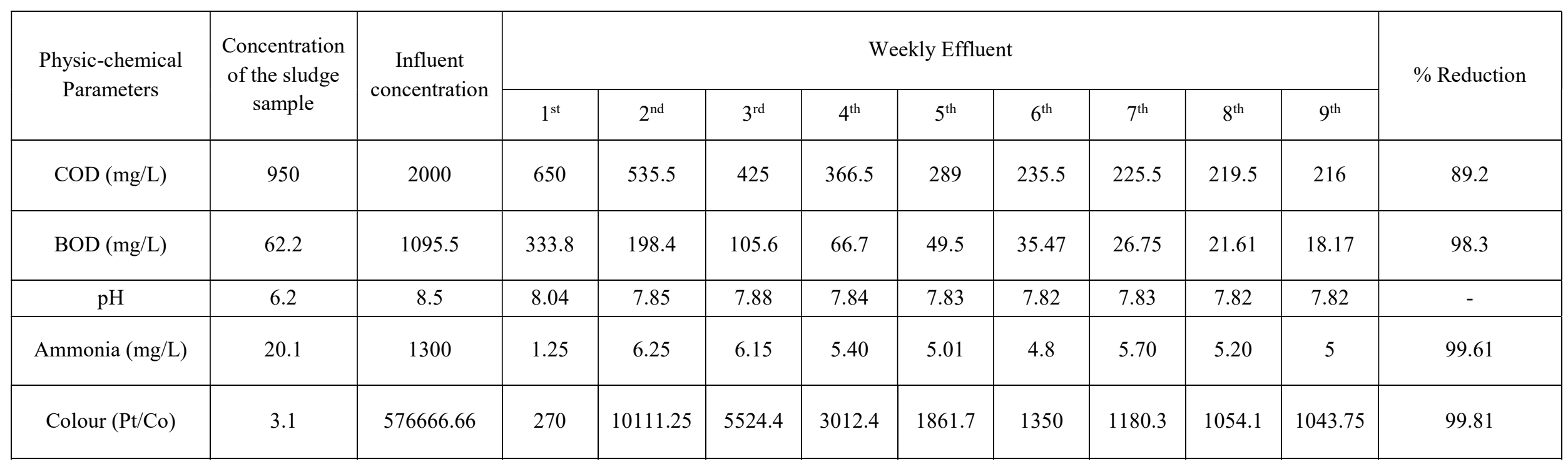

